\title{
Papers
}

\section{Trends in blood pressure over 10 years in adolescents: analyses of cross sectional surveys in the Northern Ireland Young Hearts project}

David Watkins, Peter McCarron, Liam Murray, Gordon Cran, Colin Boreham, Paula Robson, Claire McGartland, George Davey Smith, Maurice Savage

\begin{abstract}
Objective To examine secular trends in blood pressure over a 10 year period between two representative cohorts of adolescents from Northern Ireland.

Design Repeat cross sectional study.

Setting Randomly selected post-primary schools from

Northern Ireland.

Participants 1015 adolescents studied between 1989 and 1990, and 2017 adolescents studied between 1999 and 2001.

Participants were aged 12 or 15 years.

Main outcome measures Systolic and diastolic blood pressure measured by one observer in each study.

Results The four groups for sex and age showed decreases in both systolic blood pressure (mean decrease $7.7 \mathrm{~mm} \mathrm{Hg}$ to 10.0 $\mathrm{mm} \mathrm{Hg}$ ) and diastolic blood pressure $(8.8 \mathrm{~mm} \mathrm{Hg}$ to $11.0 \mathrm{~mm}$ $\mathrm{Hg}$ ). These decreases were not accounted for by adjustment for potential confounders including age, height, body mass index, smoking, physical activity, aerobic fitness, and stratification of school by education board area and type. The findings were not altered by additional adjustment for social class, pubertal status, birth weight, and infant feeding. No evidence was found of systematic variation between observers.

Conclusions Substantial decreases in systolic and diastolic blood pressure over the past decade in adolescents from Northern Ireland are likely to have important benefits to public health and may help offset the increasing risk of cardiovascular disease due to increases in obesity.
\end{abstract}

\section{Introduction}

Raised blood pressure is a major risk factor for cardiovascular disease. ${ }^{1}$ It tracks relatively well from youth to adulthood, making blood pressure in youth a useful predictor of essential hypertension in adulthood. ${ }^{23}$ Patterns of risk factors in populations, such as raised blood pressure, are not static over time, and predate subsequent changes in patterns of cardiovascular disease. ${ }^{4}$ Evidence from the United States and worldwide shows that the mean blood pressure of adults has decreased over the past two decades. ${ }^{5}{ }^{6}$ Fewer data are available on trends in youth; findings from the United States have been inconsistent, whereas in the United Kingdom, secular decreases in blood pressure have been noted in successive cohorts of university students. ${ }^{7-9}$

Trends in blood pressure in adolescents are a marker of the future population burden of cardiovascular disease and may be of particular relevance in areas with high disease rates. ${ }^{10}$ We examined trends in blood pressure in representative samples of adolescents in Northern Ireland, a region with a consistently high prevalence of cardiovascular disease. ${ }^{11}$

\section{Participants and methods}

The first Young Hearts study (YH1990) was carried out in 1989-90 to evaluate the status of major modifiable coronary risk factors, including blood pressure, within the adolescent population of Northern Ireland. Random samples of males and females aged 12 and 15 years participated, with around 250 participants in each of the four groups for age and sex. Details of the study design are presented elsewhere. ${ }^{12}$ A further cross sectional survey-Young Hearts 2000 (YH2000)-was carried out in 19992001. Around 500 adolescents in each of the four groups were recruited through post-primary schools. The sampling procedure of both surveys sought to take account of the structure of secondary education within Northern Ireland, both by selection policy (grammar and non-grammar) and geographical spread. Schools were stratified by education board area and by type of school. A two stage cluster sample of adolescents was obtained from each stratum. The primary sampling units were schools, randomly selected with probabilities proportional to school size: 16 schools took part in the first study and 36 in the second (two schools participated in both). The secondary units for study were the adolescents themselves, randomly selected from the four groups. The number of adolescents in each group was proportional to the corresponding population number. Screening took place at schools during normal school hours.

\section{Blood pressure measurement}

In each study, blood pressure readings were carried out by one observer. The observers were both paediatricians, received additional training from prerecorded tapes, and became familiar to the participants as the study protocol was carried out.

The procedure was explained to participants in advance. Tight clothing was removed from the arm, and blood pressure was measured with participants sitting after at least five minutes' rest. Measurements were taken with the UK random-zero Hawksley sphygmomanometer. ${ }^{13}$ Instruments were calibrated by the same laboratory before both studies: two instruments were used in the first study and three in the second. They were checked for accuracy at intervals by comparison with a standardised sphygmomanometer. The same standard cuff size was used in both surveys. This adult cuff covered at least two thirds of the upper arm's length, and the bladder encircled the arm's circum- 
Table 1 Mean (SD) systolic and diastolic blood pressures in participants from Young Hearts studies, 1990 and 2000

\begin{tabular}{|c|c|c|c|c|c|c|}
\hline \multirow{2}{*}{$\begin{array}{l}\text { Age; blood pressure reading (mm } \\
\mathrm{Hg} \text { ) }\end{array}$} & \multicolumn{2}{|c|}{ Males } & \multirow[b]{2}{*}{$P$ value } & \multicolumn{2}{|c|}{ Females } & \multirow[b]{2}{*}{$P$ value } \\
\hline & 1990 & 2000 & & 1990 & 2000 & \\
\hline 12 years: & $\mathrm{n}=247$ & $\mathrm{n}=530$ & & $\mathrm{n}=248$ & $\mathrm{n}=514$ & \\
\hline Systolic & 111.0 (11.6) & $102.9(11.6)$ & $<0.001$ & 111.5 (12.2) & $104.2(12.1)$ & $<0.001$ \\
\hline Diastolic & 67.9 (9.5) & 59.1 (8.7) & $<0.001$ & $70.9(9.1)$ & $60.4(8.6)$ & $<0.001$ \\
\hline 15 years: & $n=249$ & $n=485$ & & $n=252$ & $\mathrm{n}=482$ & \\
\hline Systolic & $123.3(12.4)$ & $113.2(12.8)$ & $<0.001$ & $118.3(11.8)$ & 109.9 (11.1) & $<0.001$ \\
\hline Diastolic & $73.4(9.4)$ & $62.5(8.4)$ & $<0.001$ & $74.3(8.8)$ & 64.5 (8.7) & $<0.001$ \\
\hline
\end{tabular}

ference. The cuff was deflated by around $2 \mathrm{~mm} \mathrm{Hg}$ each second and was completely deflated between readings. Systolic blood pressure was expressed as the Korotkoff phase I value. In adults, Korotkoff V (disappearance of pulse sounds) is used for the diastolic phase, whereas in young people pressure applied at the antecubital fossa may eliminate the fifth phase so that sounds persist down to $0 \mathrm{~mm} \mathrm{Hg} .{ }^{14}$ We therefore used the Korotkoff IV value (muffling of pulse sounds) for participants aged 12 and the Korotkoff $\mathrm{V}$ value for participants aged 15 . The first study used the means of two separate readings taken close together, but time constraints in the second study allowed only one reading on each participant. All readings were taken to the nearest $2 \mathrm{~mm}$ Hg.

Height was measured to the nearest millimetre and weight to the nearest $100 \mathrm{~g}$. In the first study pubertal status was assessed by a modified Tanner score, ${ }^{15}$ whereas in the second study it was assessed by a paediatrician (DCW) on the basis of non-genital secondary hair growth, vocal timbre, body habitus, and muscular development, and breast development in females. Cardiorespiratory fitness was estimated in both studies by indirect calculation of oxygen consumption at maximal dynamic effort $\left(\mathrm{VO}_{2} \mathrm{max}\right)$ in a $20 \mathrm{~m}$ shuttle run. ${ }^{16}$ Smoking status was assessed as part of a confidential self-report questionnaire completed by each participant; regular smoking was defined as consumption of one or more cigarettes a week. Birth weight of participants was recalled by parents as part of a confidential parental questionnaire. Social class was based on the current occupation of the head of the household and classified according to the 1990 standard occupational classification of the Office of Population, Censuses, and Surveys.

To check for any variation between observers in blood pressure measurements, the observers took readings from 50 randomly selected adolescents within the study age range from a non-participating Belfast school. The first observer used one sphygmomanometer for 25 measurements and another for the remaining 25 measurements. The order of instruments was reversed for the second observer.

\section{Statistical analysis}

We performed separate analyses for each of the four groups. Continuous variables and categorical variables in both studies were compared by $t$ tests and $\chi^{2}$ tests, respectively. Multivariate regression analysis was used to estimate the changes in mean systolic and diastolic blood pressures between the two studies. As unadjusted findings for the complete cohorts were similar to those for adolescents without missing data on confounders, we only present the data for participants with complete data. All data were analysed with SPSS for Windows version 11.0.

\section{Results}

The response rate for the second study was lower than that for the first $(65.3 \%$ compared with $79.3 \%)$. Reasons for nonparticipation were similarly distributed between both studies:
$40 \%$ of respondents objected to a blood test, $26 \%$ were not interested in taking part, $16 \%$ were unwilling to miss schoolwork, and $4 \%$ were unwilling to undergo a fitness test. On the basis of limited self-reported anthropometric data from non-participants, body mass index (weight $(\mathrm{kg}) /\left(\right.$ height $\left.(\mathrm{m})^{2}\right)$ ) was 0.9 lower in non-participants than in participants.

Although there was disagreement between the observers for some blood pressure readings, as evidenced by the large standard deviations of the differences between the two observers (mean (SD) difference: systolic $0.10(10.40) \mathrm{mm} \mathrm{Hg}$; diastolic $0.24(10.76) \mathrm{mm} \mathrm{Hg}$ ), there was no evidence of systematic variation between them, with similar mean systolic and diastolic blood pressures being recorded by both. In regression models with systolic and diastolic blood pressure as the dependent variables, and the effects of participant, machine, and observer as explanatory variables, there was no evidence that observer effect had influenced blood pressure measurement (data not shown).

The analyses in tables 2 and 3 are based on participants with complete data, representing $99 \%$ of the original cohorts. We found consistent differences in mean blood pressure between both sexes, males tending to have higher systolic and lower diastolic blood pressure than age matched females (table 1). These findings remained largely unchanged between the two studies. Correlations between systolic and diastolic blood pressure were of a similar order ( 0.5 to 0.65$)$ in both studies and for all four groups.

Table 2 shows the summary statistics for potential confounding or mediating variables. Mean height increased substantially in the four groups (by $1.9 \mathrm{~cm}$ to $3.0 \mathrm{~cm}, \mathrm{P}<0.001$ for each group) as did mean weight (by $1.5 \mathrm{~kg}$ to $4.2 \mathrm{~kg}, \mathrm{P}<0.001$ to $\mathrm{P}=0.04$ ), with the largest increases among 12 year olds. Mean body mass index only increased significantly in 12 year old females. Mean birth weight changed little between the first and second study (3372 $\mathrm{g}$ versus $3408 \mathrm{~g}$, respectively; $\mathrm{P}=0.10$ ). The proportion of females of both ages who smoked regularly, increased. Mean maximal aerobic fitness and mean habitual physical activity showed more favourable trends in males. The proportion of participants who were breast fed as infants increased in all four groups over the 10 year period, as did the proportion from a non-manual background (59.2\% versus $72.8 \%$; $\mathrm{P}<0.001)$.

Table 3 shows the change in mean systolic and diastolic blood pressure for the four groups between the first and second study, unadjusted and adjusted for age, height, body mass index, smoking status, physical activity, and stratification of school. Substantial decreases were found consistently across all four groups for both systolic blood pressure (mean unadjusted decrease 7.7 $\mathrm{mm} \mathrm{Hg}$ to $10.0 \mathrm{~mm} \mathrm{Hg}$ ) and diastolic blood pressure $(8.8 \mathrm{~mm}$ $\mathrm{Hg}$ to $11.0 \mathrm{~mm} \mathrm{Hg}$ ); this represents an annual decline of 0.73 $\mathrm{mm} \mathrm{Hg}$ to $1.01 \mathrm{~mm} \mathrm{Hg}$ and $0.89 \mathrm{~mm} \mathrm{Hg}$ to $1.09 \mathrm{~mm} \mathrm{Hg}$, respectively. Additional modelling, controlling for age, height, body mass index, smoking status, physical activity, stratification of school, breast feeding, and fitness, and then additionally control- 
Table 2 Characteristics of participants of Young Hearts studies, 1990 and 2000. Values are means (standard deviations) unless stated otherwise

\begin{tabular}{|c|c|c|c|c|c|c|c|c|c|c|c|c|}
\hline \multirow[b]{3}{*}{ Characteristics } & \multicolumn{6}{|c|}{ Participants aged 12} & \multicolumn{6}{|c|}{ Participants aged 15} \\
\hline & \multicolumn{3}{|c|}{ Males } & \multicolumn{3}{|c|}{ Females } & \multicolumn{3}{|c|}{ Males } & \multicolumn{3}{|c|}{ Females } \\
\hline & 1990 & 2000 & $\begin{array}{c}P \\
\text { value }\end{array}$ & 1990 & 2000 & $\begin{array}{c}P \\
\text { value }\end{array}$ & 1990 & 2000 & $\begin{array}{c}P \\
\text { value }\end{array}$ & 1990 & 2000 & $\begin{array}{c}P \\
\text { value }\end{array}$ \\
\hline Sample size & 251 & 530 & & 248 & 514 & & 249 & 485 & & 252 & 482 & \\
\hline Age (years) & $12.51(0.28)$ & $\begin{array}{l}12.53 \\
(0.28)\end{array}$ & 0.46 & $12.49(0.34)$ & $\begin{array}{l}12.50 \\
(0.27)\end{array}$ & 0.56 & $15.47(0.30)$ & $\begin{array}{l}15.48 \\
(0.28)\end{array}$ & 0.61 & $15.51(0.29)$ & $\begin{array}{l}15.48 \\
(0.29)\end{array}$ & 0.15 \\
\hline Height $(\mathrm{cm})$ & $149.8(7.9)$ & $152.3(7.7)$ & $<0.001$ & $150.8(7.5)$ & $153.7(7.1)$ & $<0.001$ & $169.0(7.1)$ & $172.0(7.9)$ & $<0.001$ & $160.6(5.9)$ & $162.5(5.8)$ & $<0.001$ \\
\hline Weight (kg) & $42.6(9.4)$ & $45.3(10.4)$ & $<0.001$ & $44.0(9.0)$ & $48.2(10.7)$ & $<0.001$ & $58.6(9.4)$ & $61.1(11.7)$ & 0.002 & $56.6(8.5)$ & $58.1(10.1)$ & 0.03 \\
\hline $\begin{array}{l}\text { Body mass index } \\
\left(\mathrm{kg} / \mathrm{m}^{2}\right)\end{array}$ & $18.9(3.3)$ & $19.4(3.4)$ & 0.06 & $19.2(2.9)$ & $20.3(3.6)$ & $<0.001$ & $20.4(2.5)$ & $20.6(3.3)$ & 0.44 & $21.9(3.1)$ & $22.0(3.4)$ & 0.85 \\
\hline $\begin{array}{l}\text { No (\%) of } \\
\text { self-reported } \\
\text { smokers }\end{array}$ & $8(3)$ & $32(6)$ & 0.14 & 4 (2) & $25(5)$ & 0.046 & $52(21)$ & $101(21)$ & 1.00 & $41(16)$ & $127(26)$ & 0.003 \\
\hline $\begin{array}{l}\text { Predicted } \mathrm{VO}_{2} \max \\
(\mathrm{ml} / \mathrm{kg} / \mathrm{min})^{*}\end{array}$ & $45.3(5.3)$ & $46.5(6.4)$ & 0.006 & $40.0(5.3)$ & $39.8(6.9)$ & 0.68 & $51.1(6.0)$ & $53.6(6.9)$ & $<0.001$ & $40.4(5.4)$ & $41.3(6.9)$ & 0.08 \\
\hline Physical activity $\dagger$ & $33.5(14.3)$ & $31.5(15.6)$ & 0.085 & $24.5(13.2)$ & $22.0(13.6)$ & 0.015 & $27.2(15.8)$ & $26.7(14.5)$ & 0.73 & $17.2(12.0)$ & $18.1(12.9)$ & 0.32 \\
\hline $\begin{array}{l}\text { Reported birth } \\
\text { weight }(\mathrm{g})\end{array}$ & 3384 (601) & $3479(560)$ & 0.042 & 3307 (512) & 3358 (511) & 0.21 & 3438 (558) & $3433(597)$ & 0.92 & 3357 (513) & 3358 (524) & 0.98 \\
\hline $\begin{array}{l}\text { No }(\%) \text { of sexual } \\
\text { maturity } \ddagger\end{array}$ & $226(90)$ & 488 (92) & 0.39 & $139(56)$ & $319(62)$ & 0.13 & $22(9)$ & 0 & $<0.001$ & 0 & 0 & 0.55 \\
\hline No (\%) breast fed & $50(20)$ & $159(30)$ & 0.003 & $57(23)$ & $159(31)$ & 0.029 & $37(15)$ & $150(31)$ & $<0.001$ & $33(13)$ & $174(36)$ & $<0.001$ \\
\hline $\begin{array}{l}\text { No }(\%) \text { of } \\
\text { non-manual } \\
\text { social class }\end{array}$ & $146(58)$ & 381 (72) & $<0.001$ & $156(63)$ & $370(72)$ & 0.026 & 147 (59) & 369 (76) & $<0.001$ & $139(55)$ & 347 (72) & $<0.001$ \\
\hline
\end{tabular}

*0xygen consumption at maximal dynamic effort in $20 \mathrm{~m}$ shuttle run.

†Scores up to 100 .

$\ddagger$ Tanner I-III.

ling for birth weight, social class, and pubertal status, had negligible effects on the results presented in table 3 (data not shown).

\section{Discussion}

Large decreases in blood pressure have occurred among adolescents aged 12 and 15 years from Northern Ireland over the decade from 1990. The magnitude of the trends is greater than previously reported, and could not be accounted for by several important mediating or confounding factors.

\section{Strengths and limitations}

Our study was population based, and participants were selected randomly. The response rate was lower for the second of the two studies (YH2000), and although there was some evidence (on the basis of self-report) that non-participants were thinner than participants, this bias would have tended to moderate the declines in blood pressure. We attempted to check for variations between observers and instruments and to minimise the possible influence of any variations. Although our observer validation exercise was of small scale and limited, particularly for reproducing blood pressure measurement technique after the 10 years from the first study, it showed no substantial effect from variation between observers. Birth weight was based on parental recall, which has been shown to give a reliable estimation of recorded birth weight in participants in YH1990. ${ }^{17}$ The Tanner scale and the visual assessment of pubertal status are both likely to be poor and arbitrary measures of the range of sexual maturity, but adjustment for pubertal status did not alter the findings and, moreover, we do not think that age at puberty will have shifted to anything except a negligible degree over the 10 years between the studies. While some caution is indicated in assessing the declines, the lack of systematic variation between observers, the use of random-zero calibrated sphygmomanometers, coupled with the consistency with published literature, indicate that the findings are unlikely to be artefactual and that bias is unlikely to explain more than a modest proportion of the declines in blood pressure noted.

\section{Comparison with other studies}

Several studies in developed countries have examined secular trends in blood pressure among children. In the United States, data from both the National Health (and Nutrition) Examination surveys and the Bogalusa heart study showed variable decreases in blood pressure in most groups of 6-17 year olds from the 1960 s to the early 1990 s. $^{718}$ In England, mean systolic blood pressure in 5-15 year olds declined by $1.4 \mathrm{~mm} \mathrm{Hg}$ to $1.7 \mathrm{~mm} \mathrm{Hg}$ between 1995 and 1998, with a small decrease in diastolic blood pressure over the same period. ${ }^{19} \mathrm{~A}$ larger number of studies have shown that decreases in blood pressure have been occurring in

Table 3 Decreases in mean blood pressure over 10 years in participants of Young Hearts studies, 1990 and 2000. Values are means (95\% confidence intervals)

Systolic blood pressure ( $\mathrm{mm} \mathrm{Hg}$ )

Diastolic blood pressure $(\mathrm{mm} \mathrm{Hg})$

\begin{tabular}{|c|c|c|c|c|}
\hline \multirow[b]{2}{*}{ Age and sex } & & \\
\hline & Unadjusted decrease & ${ }^{*}$ Adjusted decrease & Unadjusted decrease & ${ }^{*}$ Adjusted decrease \\
\hline \multicolumn{5}{|l|}{12 years: } \\
\hline Males & 8.1 (6.4 to 9.9) & 9.5 (8.0 to 11.1) & 8.8 (7.4 to 10.2) & 9.7 (8.4 to 11.0 ) \\
\hline Females & 7.7 (5.9 to 9.5$)$ & 10.4 (8.7 to 12.0$)$ & 10.5 (9.1 to 11.8) & 11.9 (10.6 to 13.1) \\
\hline \multicolumn{5}{|l|}{15 years: } \\
\hline Males & 10.0 (8.1 to 12.0$)$ & 11.6 (9.8 to 13.3$)$ & 11.0 (9.6 to 12.4) & 11.6 (10.3 to 12.9) \\
\hline Females & 8.4 (6.7 to 10.2$)$ & 8.7 (7.0 to 10.3$)$ & 9.8 (8.5 to 11.1$)$ & 10.2 (8.9 to 11.5$)$ \\
\hline
\end{tabular}

$\mathrm{P}<0.001$ for all groups (unadjusted and adjusted).

${ }^{*}$ Adjusted for body mass index, age, height, physical activity score, self-reported smoking, and stratification. 
young adults in Europe and the United States over the 50 years from $1948 .{ }^{20}$

\section{Explanation of findings}

Factors responsible for these secular decreases in blood pressure have not yet been established. The downward trend seems to be occurring despite positive associations between blood pressure in children and height and indices of fatness, both of which increased between the two Young Hearts studies (and may account for the greater adjusted mean decreases compared with the unadjusted decreases). ${ }^{21}{ }^{22}$ Similar findings have been observed in the Health Survey for England, when increases in body mass index were accompanied by decreases in blood pressure. $^{19}$

Birth weight, as the most accessible marker of intrauterine growth, has shown a consistent inverse association with subsequent blood pressure, and it has been proposed that raised blood pressure may be a response to fetal undernutrition, causing long term changes in arterial structure in the child. ${ }^{23}$ An estimated increase in birth weight of around $1000 \mathrm{~g}$ would be required to produce a $2 \mathrm{~mm} \mathrm{Hg}$ decrease in systolic blood pressure in people aged $50,{ }^{23}$ and even this effect size has recently been questioned, with the suggestion that the inverse association may reflect the impact of selective emphasis of particular results and inappropriate adjustment for confounders. ${ }^{24}$ The relatively small secular changes in mean birth weight (from - $11 \mathrm{~g}$ to $94 \mathrm{~g}$ for the different groups) between our two cohorts would not by themselves explain the magnitude of decreases in blood pressure.

Alterations in salt intake may be important. A recent systematic review of trials of salt restriction reported only small reductions in blood pressure..$^{25}$ In adolescents randomised in infancy to a low or a normal sodium diet, however, systolic and diastolic blood pressure were lower after 15 years in those in the intervention arm, suggesting that sodium restriction in infancy may have greater effects on later blood pressure than salt reductions in adulthood, ${ }^{26}$ and although these findings should be interpreted with caution, as they are based on incomplete follow up, they are, nevertheless, provocative.

\section{Implications for public health}

Our observations suggest that several of the major determinants of adult blood pressure are set in train in early life. Mild increases of blood pressure in early life are known to increase long term cardiovascular risk. ${ }^{10}$ It is therefore encouraging that blood pressure levels seem to have fallen over time in this population, and there are likely to be considerable public health benefits in such a population decrease if it is sustained into adult life. It may also be that benefits from decreasing blood pressure offset increasing cardiovascular risk from population increases in obesity.

Contributors: CB, MS, LM, and GC designed the study. DW and CMcG collected the data along with Sinead McElhone, Rose O'Neill, and Oriel Ward GC and DW analysed the data. DW wrote the first draft and PMcC, GDS, $\mathrm{LM}, \mathrm{CB}, \mathrm{MS}$, PR, CMcG, and GC contributed to writing the final version of the paper. MS will act as guarantor for the paper.

Funding: The Young Hearts 2000 project was funded by a grant from the Department of Health and Social Services in Northern Ireland. PMcC is funded by a Department of Health public health career scientist award.

Competing interests: None declared.

Ethical approval: This study was approved by the research ethics committee of Queen's University of Belfast. Written consent for participation was obtained from each participant and the participant's parent or guardian.

1 Stamler J, Stamler R, Neaton JD. Blood pressure, systolic and diastolic, and cardiovascular risks. US population data. Arch Intern Med 1993;153:598-615.

2 Bao W, Threefoot SA, Srinivasan SR, Berenson GS. Essential hypertension predicted by tracking of elevated blood pressure from childhood to adulthood: the Bogalusa Heart Study. Am J Hypertens 1995;8:657-65.

\section{What is already known on this topic}

Trends in blood pressure in early life are a marker of subsequent cardiovascular risk

Studies have shown secular decreases in blood pressure in adults, but evidence is less consistent for younger populations

\section{What this study adds}

Decreases in blood pressure, not explained by change in body composition or birth weight, have occurred in adolescents in Northern Ireland over the past decade

The major determinants of adult blood pressure seem to be set in early life

Potentially modifiable determinants need to be ascertained

Lauer RM, Clarke WR. Childhood risk factors for high adult blood pressure: the muscatine study. Pediatrics 1989;84:633-41.

Thom TJ. International mortality from heart disease: rates and trends. Int J Epidemiol Thom TJ. Intern
1989;18:S20-8.

5 Burt VL, Culter JA, Higgins M, Horan MJ, Labarthe D, Whelton P, et al. Trends in the prevalence, awareness, treatment, and control of hypertension in the adult US population. Data from the health examination surveys, 1960 to 1991. Hypertension 1995;26:60-9.

6 Kuulasmaa K, Tunstall-Pedoe H, Dobson A, Fortmann S, Sans S, Tolonen H, et al. Estimation of contribution of changes in classic risk factors to trends in coronary-event rates across the WHO MONICA Project populations. Lancet 2000;355:675-87.

7 Gidding SS, Bao W, Srinivasan SR, Berenson GS. Effects of secular trends in obesity on coronary risk factors in children: the Bogalusa Heart Study J Pediatr 1995:127:868-74.

- Luepker RV Jacobs DR, Prineas RJ, Sinaiko AR. Secular trends of blood pressure and body size in a multi-ethnic adolescent population: 1986 to 1996 . J Pediatr body size in a
1999; $134: 668-74$

9 McCarron P, Okasha M, McEwen J, Davey Smith G. Changes in blood pressure among students attending Glasgow University between 1948 and 1968: analyses of cross sectional surveys. BMJ 2001;322:885-9.

10 McCarron P, Davey Smith G, Okasha M, McEwen J. Blood pressure in young adulthood and mortality from cardiovascular disease. Lancet 2000;355:1430-1.

11 Uemura K, Pisa Z. Trends in cardiovascular disease mortality in industrialized countries since 1950. World Health Stat Q 1988;41:155-78.

12 Boreham C, Savage JM, Primrose D, Cran G, Strain J. Coronary risk factors in schoolchildren. Arch Dis Child 1993;68:182-6.

13 Wright BM, Dore CF. A random-zero sphygmomanometer. Lancet 1970;337-8.

14 De Swiet M, Dillon MJ, Littler W, O'Brien E, Padfield PL, Petrie JC. Measurement of blood pressure in children. Recommendations of a working party of the British Hypertension Society. BMJ 1989;299:497.

15 Tanner JM. Growth at adolescence. Oxford: Blackwell, 1962

16 Boreham CA, Paliczka VJ, Nichols AK. A comparison of the PWC170 and 20-MST tests of aerobic fitness in adolescent schoolchildren.J Sports Med Phys Fitness 1990;30:19-23.

17 Walton KA, Murray LJ, Gallagher AM, Cran GW, Savage MJ, Boreham C. Parental recall of birthweight: a good proxy for recorded birthweight? Eur J Epidemiol 2000;16:793-6.

18 Roberts J. Cardiovascular conditions of children aged 6-11 years and youths 12-17 years. United States, 1963-1965 and 1966-1970. National Center for Health Statistics, Vital Health Stat Series11 (166), 1978.

19 Department of Health. Health Survey for England: trend data for children 1995-1998, children's reference tables '98. London: Department of Health, 2002.

20 McCarron P, Davey Smith G, Okasha M. Secular changes in blood pressure in childhood, adolescence and young adulthood: systematic review of trends from 1948 to 1998. J Hum Hypertens. 2002;16:677-89.

21 Kotchen JM, McKean HE, Neill M, Kotchen TA. Blood pressure trends associated with changes in height and weight from early adolescence to young adulthood.J Clin Epidemiol 1989;42:735-41.

22 Berenson GS, Wattigney WA, Webber LS. Epidemiology of hypertension from childhood to young adulthood in black, white, and Hispanic population samples. Public Health Rep 1996;111(suppl 2):3-6.

23 Huxley RR, Shiell AW, Law CM. The role of size at birth and postnatal catch-up growth in determining systolic blood pressure: a systematic review of the literature.J Hypertens 2000;18:815-31.

24 Huxley R, Neil A, Collins R. Unravelling the fetal origins hypothesis: is there really an inverse association between birthweight and subsequent blood pressure? Lancet 2002;360:659-65.

25 Ebrahim S, Davey Smith G. Lowering blood pressure: a systematic review of sustained effects of non-pharmacological interventions. J Public Health Med 1998;20:441-8.

26 Geleijnse JM, Hofman A, Witteman JC, Hazebroek AA, Valkenburg HA, Grobbee DE. Long-term effects of neonatal sodium restriction on blood pressure. Hypertension 1997;29:913-7.

(Accepted 6 May 2004)

doi $10.1136 /$ bmj.38149.510139.7C 
Department of Child Health, Queens University of Belfast, Institute of Clinical Science, Royal Victoria Hospital, Belfast BT12 6JB

David Watkins consultant

Maurice Savage professor

Department of Epidemiology and Public Health, Queens University of Belfast

Peter McCarron senior lecturer

Liam Murray senior lecturer

Gordon Cran senior lecturer in medical statistics

Department of Applied Medical Sciences and Sports Studies, University of Ulster, Newtownabbey BT37 0QB
Colin Boreham professor of sport and exercise science

Northern Ireland Centre for Diet and Health, University of Ulster, Coleraine BT52 1SA

Paula Robson research fellow

Claire McGartland research associate

Department of Social Medicine, University of Bristol, Bristol BS8 2PR George Davey Smith professor of clinical epidemiology

Correspondence to: Dr David Watkins, Stepping Hill Hospital, Stockport SK2 7JE david.watkins@stockport-tr.nwest.nhs.uk 